\title{
Management of epilepsy and pregnancy
}

\section{Thomas SV}

\section{Indian Registry of}

Epilepsy and Pregnancy, Department of Neurology, Sree Chitra Tirunal Institute for Medical Sciences and Technology, Trivandrum. 695011, India

\section{Correspondence:}

Sanjeev V. Thomas,

E-mail:

sanjeev@sctimst.ker.nic.in $\begin{array}{lr}\text { Received } & : \text { 29-04-05 } \\ \text { Review completed }: \text { 09-06-05 } \\ \text { Accepted } & : \text { 04-10-05 } \\ \text { PubMed ID } & : 16534170 \\ \text { J Postgrad Med 2006;52:57-64 }\end{array}$

\begin{abstract}
Epilepsy is recognized as the commonest serious neurological disorder in the world. Women with epilepsy (WWE) experience several gender-related physical and social problems. They constitute high obstetric risk because of reduced fertility, risk of seizures during pregnancy, and complications of pregnancy. Hormonal and other factors can alter the pharmacokinetics of antiepileptic drugs (AED) during pregnancy and puerperium. Antenatal exposure to AEDs, particularly at higher dosage and in polytherapy, increases the risk of fetal malformation. Recent reports raise the possibility of selective developmental language deficits and neurocognitive deficits with antenatal exposure to AEDs. There are concerns regarding the effect of traces of AEDs that pass to the infant during breast-feeding. The pre conception management is the cornerstone for epilepsy care in WWE. A careful reappraisal of each case should ascertain the diagnosis, the need for continued AED therapy, selection of appropriate AEDs, optimization of the dosage, and prescription of folic acid. During pregnancy, the fetal status needs to be monitored with estimation of serum a-feto-protein and ultrasound screening for malformations. The dosage of AEDs can be adjusted according to clinical requirement and blood levels of AEDs. Several institutions recommend oral vitamin K toward the end of pregnancy when enzymeinducing AEDs are prescribed because the latter may potentially predispose the new born to hemorrhagic disease, but recent reports indicate that such a risk is practically negligible. WWE who are using enzymeinducing AEDs (phenobarbitone, primidone, phenytoin, carbamazepine, and oxcarbazepine) need to know that these AEDs may lead to failure of oral contraception.
\end{abstract}

KEY WORDS: Antenatal ultrasonography, antiepileptic drug, congenital malformation, epilepsy, gender issues, pregnancy, prevention, reproductive dysfunction, teratogenesis, treatment pilepsy is a common neurological disorder with a prevalence rate of approximately $0.5 \%$ in most communities. It is estimated that there are over 2.5 million women with epilepsy (WWE) in India, ${ }^{[1]}$ with up to $52 \%$ of them being in the reproductive age group. ${ }^{[2]}$ People with epilepsy, especially women, experience tremendous social stigma and alienation in life. Despite progress in medical and surgical therapy, better social acceptance, and favorable legal stand, WWEs are less, often married (59\%), when compared with others in the community (65\%). ${ }^{[3,4]}$ Neurologists and obstetricians are increasingly faced with WWE during pregnancy, but apparently are not adequately informed about their optimal management. ${ }^{[5,6]}$ Several important aspects need to be attended to, which manage pregnancy in WWE: Pregnancy influences the natural history of epilepsy and seizures are likely to worsen in about one-third of them; the bioavailability of antiepileptic drugs (AEDs) may change considerably owing to alterations in its pharmacodynamics and kinetics and most AEDs are potentially teratogenic and hence may increase the risk of fetal malformations.

\section{Effect of Pregnancy on Epilepsy}

\section{Hormonal aspects of epilepsy}

Experimental and clinical studies have shown that seizures are influenced by the female sex hormones estrogen and progesterone. ${ }^{[7,8]}$ In general, estrogen lowers the seizure threshold and progesterone elevates it. In most experimental animal models, estrogen lowers the threshold for seizures induced by electroshock, kindling, pentylenetetrazol, and other agents. Topical brain application or intravenous administration of estradiol in rabbits increases spontaneous paroxysmal spike discharges, especially when there is a pre-existing cortical lesion. ${ }^{[9]}$ Progesterone, on the other hand, reduces spontaneous and induced epileptiform discharges. ${ }^{[10]}$ Similar observations have been made in human beings also. Conjugated estrogen, when administered intravenously, activated epileptiform discharges in 11 of 16 women with clinical seizures. ${ }^{[11]}$ In another study, four of seven women with partial epilepsy showed significant reduction in interictal spike frequency when progesterone was infused intravenously. ${ }^{[12]}$ 


\section{Epileptic syndromes during pregnancy}

Several mechanisms, including syndromes ${ }^{[13]}$ such as metabolic derangement, eclampsia, and cerebral venous sinus thrombosis, can induce seizures during pregnancy and postpartum period, epilepsy being the commonest amongst them. Majority of WWE have had seizures even before pregnancy. Rarely, some WWE may experience seizures only during pregnancy, which is termed gestational epilepsy. Such women would be seizurefree between pregnancies. Another subgroup (gestational onset epilepsy) may have their first seizure during pregnancy and thereafter may continue to get spontaneous recurrent seizures. Approximately 1-2\% of WWE may experience status epilepticus (SE) during pregnancy, which is associated with high morbidity and mortality.

\section{Effect of pregnancy on seizure frequency}

Pregnancy has a variable effect on seizure frequency. Seizure frequency may remain unchanged or decreases in two-third of WWE, whereas it may increase in others. ${ }^{[14]}$ Seizure frequency may also vary between pregnancies in the same woman. There can be diverse patterns of seizure frequency during pregnancy. WWE may have a stable pattern with seizure frequency remaining more, less, or unchanged throughout the entire period of pregnancy. Others may have an unstable pattern wherein the seizure frequency may vary widely and often unpredictably during different months of pregnancy. In a recent study it was observed that nearly $61 \%$ patients had a stable pattern and 39\% women had an unstable pattern. ${ }^{[15]}$ Approximately $1 \%$ of them had SE. Diverse mechanisms have been put forward to explain the change in seizure frequency during pregnancy. Apart from the reproductive hormones, several other factors such as noncompliance and decrease in blood levels of free form of AED, influence seizures during pregnancy (Table $1)$.

\section{Effect of epilepsy on pregnancy \\ Infertility}

It is generally considered that WWE have reduced fertility rate. ${ }^{[3,16,17]}$ The proportion of women who get married and the age at marriage can influence the fertility rate. The demographic, social, economic, and medical factors that influence marriage in WWE need further examination. ${ }^{[18]}$ Polycystic ovarian disease (PCOD), an important cause for infertility, may occur in approximately $10 \%$ of women in the community. It should be distinguished from polycystic ovaries that may be seen in as much as $20 \%$ of women in the community. ${ }^{[19]}$ The European-American consensus workshop requires two of the

\section{Table 1: Possible causes of increase in seizure frequency} during pregnancy

\begin{tabular}{ll}
\hline Mechanism & Examples \\
\hline Hormonal & $\begin{array}{l}\text { Changes in levels of estrogens and progesterone } \\
\text { Metabolic }\end{array}$ \\
Psychological & $\begin{array}{l}\text { Stress, anxiety related to the pregnancy, or other } \\
\text { causes } \\
\text { Decrease in serum levels of AEDs owing to } \\
\text { Pharmacokinetics } \\
\text { noncompliance, delusional effect, or altered drug } \\
\text { clearance } \\
\text { Sleep deprivation and physical strain }\end{array}$ \\
\hline
\end{tabular}

three criteria (oligo/anovulaton, clinical, or biochemical signs of hyperandrogenism and polycystic ovaries) to be present in order to diagnose PCOD. ${ }^{[20]}$ It appears that WWE have an increased tendency for PCOD. ${ }^{[21]}$ Use of sodium valproate (VPA) had been shown to correlate with the presence of PCOD, which reverses when VPA is substituted by another AED. ${ }^{[22]} \mathrm{A}$ recent consensus report has recommended that if a reproductive endocrine disorder is found in WWE, AED treatment should be reviewed to ensure that it is correct for the particular seizure type and that it is not contributing to the endocrine problem. The possible benefits of a change in treatment must be balanced against seizure control and the cumulative side effect of alternative agents. ${ }^{[23]}$

\section{Complications of pregnancy}

It is uncertain whether WWE have more complications of pregnancy. A recent prospective study of 643 pregnancies in WWE showed that the frequencies of several complications of pregnancy in WWE were comparable with those without epilepsy, except for spontaneous abortions, anemia, ovarian cyst, and fibroid uterus. ${ }^{[24]}$ Nevertheless, several other studies have not demonstrated an excess risk of abortion in WWE. ${ }^{[14,25,26]}$ There are conflicting reports regarding the increased risk of nonpreteinuric hypertension, ${ }^{[27]}$ pre-eclampsia, eclampsia, and abruptio placenta in WWE. Frequency of cesarean section may be increased for WWE, although most of them can have normal vaginal delivery ${ }^{[28]}$ Uterine inertia, seizures, and failure of progression of labor are usual causes of cesarian section (Table 2). ${ }^{\left[{ }^{[2]}\right.}$ A generalized seizure at term can cause transient fetal asphyxia, as evidenced by cardiotocography. Fetal bradycardia, reduced variability, and decelerations are seen for approximately 15 min after grand mal seizure. ${ }^{[30]}$ In general, most WWEs can expect an uneventful pregnancy and delivery.

\section{Effect of epilepsy and AED on fetus}

Effects on fetal and neonatal anthropometric parameters

Minor variations in anthropometric features have been observed in infants of mothers with epilepsy. Low birth weight and reduced length and head circumference have been observed in certain studies. A recent study has shown that infants exposed to AEDs may have increased tendency for minor facial anthropometric variations when compared to normal babies. However, this variation was not correlated with

\section{Table 2: Indications for cesarean section}

\author{
Elective cesarean section \\ Substantial neurological or mental retardation \\ Reduced cooperation of the patient for labor \\ Very poor control of seizures \\ Daily complex partial seizures \\ Weekly tonic-clonic seizures \\ Uterine inertia \\ Failure of induction of labor \\ Heavy sedation for patient \\ Emergency cesarean section \\ Generalized seizures during labor or near term \\ Fetal asphyxia \\ Other obstetric indications
}


any specific AED or with polytherapy compared with monotherapy. ${ }^{[31]}$ Physiological impairments that were noticed in the newborns include low Apgar score and failure to thrive. Babies born to mothers taking phenobarbitone may experience mild irritability owing to the withdrawal effect of phenobarbitone, but it is likely to disappear in a few days' time. Rarely, withdrawal seizures have been noticed in exposed neonates.

\section{Malformations}

The risk of malformation in the baby is one of the major concerns for WWE. Deviations from normal development can be classified into major malformations and minor anomalies. Malformations refer to major abnormalities that require surgical intervention within the first year of life or are likely to result in significant impairment and disability, e.g., neural tube defects (NTDs), congenital heart disease, or cleft palate. Anomalies are minor deviations from normal development that may not cause significant impairment or disability, e.g., Hypertelorism, acral hypoplasia of nails.

In 1964, Janz first drew attention to the possible teratogenic effects of AEDs. ${ }^{[32]}$ The first systematic study in English language was by Meadow in 1968. ${ }^{[33]}$ Since then several fetal syndromes such as fetal hydantoin syndrome, fetal ethosuximide syndrome and fetal phenobarbitone syndrome have been described. The commonly observed malformations may affect cardiovascular system, gastrointestinal system, skeletal and connective tissues, and central nervous system (Table 3). ${ }^{[34]}$ It had been observed that the malformations observed with different AEDs share much in common and are often indistinguishable. Hence, they are often referred to as fetal AED syndromes.

A joint European prospective study of human teratogenesis associated with maternal epilepsy has recently shown that most of the commonly used AEDs carry a relative risk of malformations when used in mono- or polytherapy (Table 4). ${ }^{[35]}$ Several groups of medical professionals have been examining this issue over many decades through registries of epilepsy and pregnancy in several countries. None of the commonly used AEDs

\section{Table 3: Incidence of malformations in women on AED}

\begin{tabular}{llr}
\hline System & Malformations & $n=243(\%)$ \\
\hline CVS & $\begin{array}{l}\text { TOF, ASD, VSD, PDA, pulm. atresia, single } \\
\text { ventricle }\end{array}$ & $66(2.0)$ \\
Craniofacial & Cleft lip, cleft palate & $59(1.8)$ \\
Skeletal & Club foot, hip dislocation etc & $29(0.9)$ \\
CNS & Neural tube defects & $23(0.7)$ \\
GIT & Esoph. Atresia, CHPS, omphalocele, hernia & $10(0.3)$ \\
& (diaphram, inguinal, umbilical) & \\
GUT & Renal agenesis, hydronephrosis, hypospadias, & $11(0.3)$ \\
& undescended testes & $45(1.4)$ \\
Others & &
\end{tabular}

The overall incidence of congenital malformations was $7.5 \%$ among 3228 children born alive of mothers treated with antiepileptic drugs (25 cohorts). ${ }^{[34]}$ Figures in parentheses indicate percentages. AED, antiepileptic drugs; ASD, atrial septal defect; CHPS, congenital hypertrophic pyloric stenosis; PDA, patent ductus arteriosus; TOF, tetrology of Fallot; VSD, ventricular septal defect.
Table 4: Relative risk for congenital malformations with exposure to various AEDs in mono- or polytherapy ${ }^{[35]}$

\begin{tabular}{lcc}
\hline Antiepileptic drug & $\begin{array}{c}\text { Number of pregnancies associated } \\
\text { with congenital malformations }\end{array}$ & RR \\
\hline Nonepileptic controls & $12 / 58(8)$ & 1.0 \\
CBZ & $4 / 14(29)$ & 4.9 \\
PB & $1 / 6(17)$ & 2.4 \\
PHT & $5 / 33(15)$ & 2.2 \\
PRM & $3 / 39(8)$ & 1.0 \\
VPA & $6 / 21(29)$ & 4.9 \\
PHT +PB & $2 / 15(13)$ & 1.8 \\
PRM +VPA & $1 / 13(8)$ & 1.0 \\
Others & $8 / 51(16)$ & 2.1 \\
\hline
\end{tabular}

CBZ, carbamazepine; PB: phenobarbitone; PHT, phenytoin; RR, relative risk; $V P A$, sodium valproate

are free of teratogenic effects. A community-based study of 1398 AED-exposed infants from Sweden $(90 \%$ as monotherapy) had shown that odds ratio for neonatal malformations was 2.52 (95\% CI: 1.43-4.68) for those exposed to VPA monotherapy compared with carbamazepine (CBZ) monotherapy. ${ }^{[36]}$ The North American Registry of Pregnancy and AED usage had recently demonstrated that antenatal use of phenobarbitone $(\mathrm{PB})$ increases the relative risk of major malformations to 4.2 compared with a background risk of $1.62 \%$. ${ }^{[37]}$ The same group has also shown that the relative risk of having an affected offspring for VPA-exposed women was 7.3 (95\% CI: 4.4-12.2; $P<0.001$ ). They had identified 16 affected cases among 149 VPA-exposed women (proportion: 10.7\%; 95\% CI: 6.3-16.9\%). The prevalence in the internal comparison group was $2.9 \%$ (95\% CI: $2-4.1 \%$; odds ratio: 4.0 , 95\% CI: 2.1-7.4; $\mathrm{P}<0.001)$ and external comparison group was $1.62 \% .{ }^{[38]}$

Several new AEDs have come in to the market in the last decade. The scope of newer AEDs in the management of epilepsy and pregnancy (Figure 1) needs careful evaluation (Table 5). It is important to remember that currently we have only meager data on the safety of newer AEDs with regard to human pregnancy and great caution should be exercised while interpreting them. Oxcarbazepine (OXB) has several pharmacological properties favorable for pregnancy. According to a recent report on 55 pregnancies with OXB (35 monotherapy), one malformation (cardiac) was observed in the offspring of a patient receiving the combination of $\mathrm{OXB}$ and $\mathrm{PB}$ and none with $\mathrm{OXB}$ monotherapy. ${ }^{\left[{ }^{[3]}\right.}$ In a series of 309 infants (from six countries) exposed to OXB (248 as monotherapy), the malformation rates were $2.4 \%$ for monotherapy and $6.6 \%$ for the adjunctive therapy group. The relative risk of malformation for OXB monotherapy appeared to be comparable with that in community. ${ }^{[40]}$

Clinical trials of lamotrigine (LTG) started in 1984 and by turn of the next decade several thousand patients had been prescribed this drug. It is a broad spectrum AED with clinical indications similar to VPA. The U.K. registry reported a higher malformation rate with VPA, 5.9\% (4.3-8.2\%; 95\% CI), than with CBZ $(2.3 \%[1.4-3.7 \%])$ or LTG $(2.1 \%$ [1.0-4.0\%]). International Lamotrigine Registry had published their results re 
Table 5: Effects of AEDs on oral contraceptives, fertility, and pregnancy

\begin{tabular}{lcll}
\hline Anti-epileptic drug & Oral contraceptiveefficacy & Fertility & Pregnancy \\
\hline Phenytoin & Reduced & Increased steroid binding globulinDecreased & Known teratogenicity \\
CBZ & $\begin{array}{l}\text { Reduced } \\
\text { Reduced }\end{array}$ & $\begin{array}{l}\text { dehydroepiandrosterone Increased steroid binding globulin } \\
\text { Increased steroid binding globulinReduced estradiol levels } \\
\text { in women exposed }>5 \text { years }\end{array}$ & $\begin{array}{l}\text { Known teratogenicity } \\
\text { Known teratogenicity }\end{array}$ \\
VPA & No effect & $\begin{array}{l}\text { Decreased dehydroepiandrosteroneIncreased testosterone } \\
\text { associated with polycystic ovaries }\end{array}$ & Known teratogenicity \\
Gabapentin & No effect & Not known & No teratogenic effect in animals \\
LTG & No effect & No effect & Less teratogenic risk \\
TPM & Reduced & Not known & Possible less teratogenic effect \\
Tiagabine & Reduced & Not known & Unknown \\
OXB & No effect & Not known & Known teratogenicity
\end{tabular}

Modified from Morrell et al. ${ }^{[47]}$

cently. ${ }^{[41]}$ Among 414 first-trimester exposures to LTG monotherapy, 12 outcomes with major birth defects were reported (2.9\% CI: $1.6-5.1 \%)$. The risk of malformations after first-trimester exposure to LTG monotherapy was similar to that observed in general population. Nevertheless, the risk of major birth defects was much higher $(12.5 \%$, 95\% CI: $6.7-$ $21.7 \%$ ) when LTG was combined with VPA in the first trimester. These preliminary results indicate that LTG may have a lesser teratogenic potential than VPA. Nevertheless, several other factors also need to be taken in to consideration. It appears that LTG and topiramate (TPM) have lower efficacy against idiopathic generalized epilepsy, when compared with VPA. In a series of 962 persons with idiopathic generalized epilepsy, one year remission was highest $(52.1 \%)$ for of persons using VPA monotherapy and lower for those using TPM (34.6\%) and LTG (16.7\%) monotherapy. ${ }^{[42]}$ Persons on LTG may experience increase in seizure frequency during pregnancy because LTG is eliminated much faster than during nonpregnant state. ${ }^{[43]}$ The concentration of LTG in breast milk is higher than that for other AEDs. ${ }^{[4+45]}$ Breast-fed infants may occasionally have blood levels in the therapeutic range. Most of the recent studies indicate that the risk of NTD in the offspring seems to be much less with LTG, when compared with VPA, but this needs further validation. ${ }^{[46]}$

There is only limited information available regarding safety of vigabatrin during pregnancy. ${ }^{[47]}$ Fewer pregnancies have been prospectively identified among women receiving gabapentin, tiagabine, TPM, and levetiracetam. Efforts are being made to systematically collect such data through registries. ${ }^{\left[{ }^{[4,49]} \text { If one }\right.}$ of the newer AEDs is the most efficacious and best tolerated AED for a woman, the general principles for pregnancy care should be followed as for the established AEDs. TPM passes freely across placenta and appears to a limited extent (60-80\%) in breast milk. Breast-fed infants had only negligible concentrations of TPM in their blood samples. ${ }^{[50]}$ Preliminary data from phase-IV studies indicate that levetiracetam has no unfavorable effects on the fetus. ${ }^{[51,52]}$

\section{Neurocognitive development and AED exposure in-utero}

Most babies born to WWE are normal. Recent reports suggest that these babies may have an increased risk of developmental delay or specific learning disabilities. ${ }^{[33-55]}$ Most of the studies are retrospective in design and do not control for all other variables. When 249 mother-child pairs were evaluated with a series of neuropsychological tests (children were 6-16 years old), those exposed to VPA had a significantly lower verbal IQ when compared with those with exposure to other AEDs or those not exposed to any AED. ${ }^{[53]}$

\section{Preconception Management}

Preconception evaluation is the most important phase in the management of epilepsy and pregnancy. WWE need to have a neurological review at this stage, in order to ascertain the diagnosis and the need for continued treatment with AEDs. Several professional groups have examined this aspect in great detail and have come out with evidence based practice guidelines. ${ }^{[57-62]}$ Most studies have shown that the risk of malformations in fetus is likely to be low with monotherapy, use of relatively lower dose, spacing of daily dose into multiple aliquots, and preconception use of folic acid. The controlled or extended release formulations of AEDs are likely to maintain a steady blood levels without much fluctuations. There is considerable variation in the risk of malformations with different AEDs even when used as monotherapy. Different AEDs carry different therapeutic efficacies against different seizure types. Physicians need to discuss these aspects with WWE and their partners and explain the rationale of AED selection. It may be possible to withdraw AED if the patient had remained seizure-free for more than 2 years. The general guidelines for AED withdrawal as for patients in remission are followed in WWE also. Persons with juvenile myoclonic epilepsy may have to continue therapy, even when they had been seizure-free for quite some time and the EEG was normal. In the case of high-risk pregnancies (with family history of NTDs or previous pregnancies with birth defects), the option of an alternate AED needs to be discussed with the patients although the second AED may also carry the potential risk. There is much debate regarding the choice of AED for women with juvenile myoclonic epilepsy who are contemplating pregnancy. The risk and benefits of VPA vs LTG or TPM needs to be discussed with them so that the patients would be able to make an informed choice. High-dosage VPA and combination of VPA and LTG may be avoided, if possible, in preconception period and early preg- 
nancy, since it carries a higher risk of fetal malformations.

Scientific opinions differ with regard to the role of periodic monitoring of blood levels of AEDs during pregnancy. Blood levels of several AEDs tend to decrease during the latter part of pregnancy (largely owing to drop in the protein-bound fraction). Nevertheless, the patients may not experience aggravation of seizures because the free drug level is not much reduced and because of the favorable hormonal effects. It is important to estimate the free drug levels if the patient experiences unexpected increase in seizures.

A universal recommendation for antenatal care includes prescription of $0.4 \mathrm{mg}$ of folic acid daily. The dosage of folic acid recommended for women with higher risk varies from l-4 mg daily in several countries. Women in developing countries may be at higher risk of folic acid deficiency owing to dietary inadequacy, infections, or concomitant use of other drugs. In India, 4-mg tablets of folic acid are not readily available. We therefore recommend that all women planning pregnancy should receive $5 \mathrm{mg}$ daily of folic acid. The general protocol for preconception management of WWE that is followed in the Indian Registry of Epilepsy and Pregnancy (IREP) ${ }^{[54]}$ is depicted in Figure 1.

\section{Management of Epilepsy During Pregnancy}

Seizures tend to improve or remain unchanged in nearly twothirds of WWE. The risk of seizures is higher in the first trimester of pregnancy and around delivery time. The policy of the IREP is to avoid any change in AEDs once pregnancy had been confirmed in a WWE. Nevertheless, in cases of polytherapy with multiple drugs, it may be possible to eliminate the third, and occasionally the second, AED after retaining the $\mathrm{AED}(\mathrm{s})$ appropriate for the seizure. It is preferable to keep the total daily dose of VPA below $1000 \mathrm{mg}$ as higher doses have been implicated with an increased risk of NTD. Care should be taken to split the daily dose in to three or four divided aliquots in order to avoid high peak levels in the blood. It is important to ensure good compliance with AEDs throughout pregnancy in order to avoid relapse of seizures. The dosage may have to be increased in some patients in the third trimester, especially if the blood levels (preferably free drug levels) are low. The risk of seizure relapse around the time of delivery is three times more than during the rest of the pregnancy. The increased risk of seizure relapse is probably related to the lack of compliance, dehydration, prolonged fasting, or effect of concomitant medications. Care should be taken to avoid such provoking factors at the time of delivery.

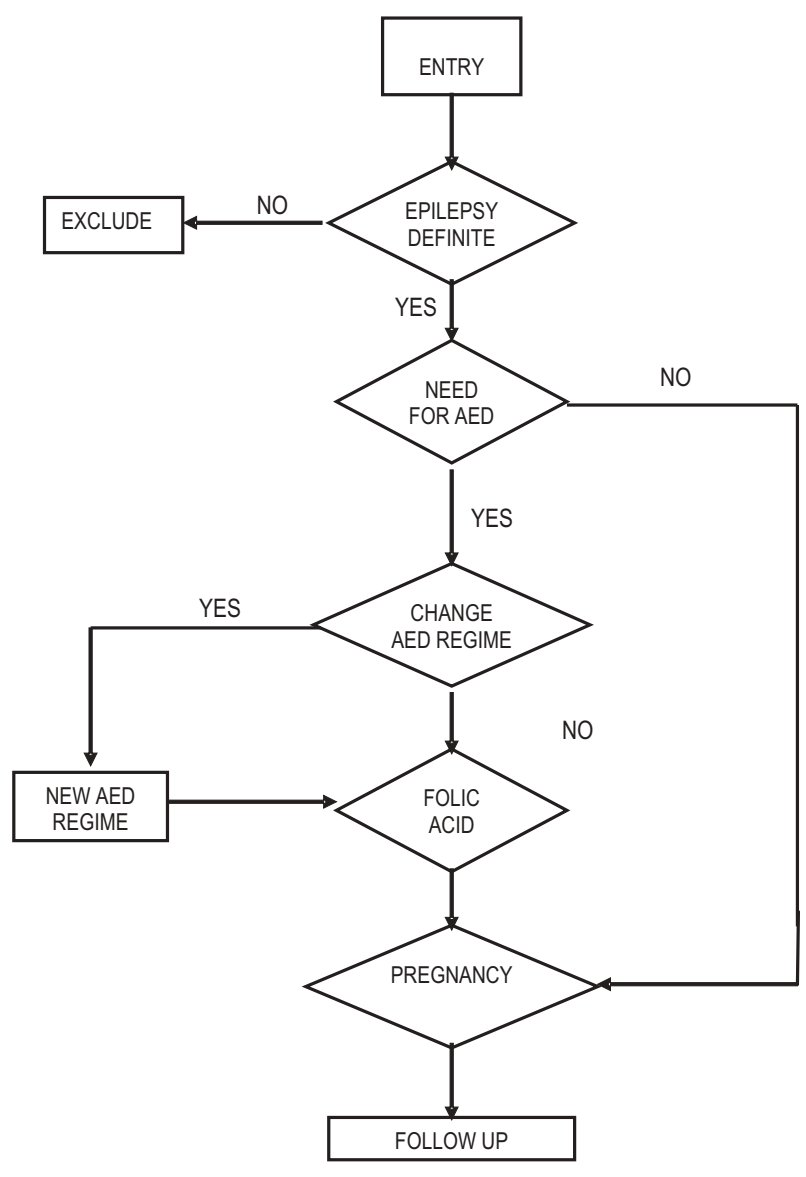

Figure 1: Algorithm for the management of epilepsy and pregnancy 
Status epilepticus can occur rarely during pregnancy (less than one percent). General guidelines for managing SE can be followed in such instances. The fetal outcome had been poor when it took a long time to control seizures.

\section{Management of Pregnancy in WWE}

The general schedule of antenatal check-up should be followed in all WWE. Folic acid supplementation should be initiated as soon as pregnancy is confirmed, if it had not been started in the preconception period.

\section{Monitoring for fetal malformations}

Monitoring for fetal malformations should be carried out towards the end of first trimester. The first line screening procedure would be estimation of serum $\alpha$-feto-protein (AFP), which tends to be elevated in cases of open NTD. Serum levels of AFP increase gradually during the first trimester and drop toward the fourth month of pregnancy. Hence, the levels should be correlated with the period of pregnancy preferably with conceptual age, calculated with the help of ultrasonography. Each laboratory needs to establish the normative values of AFP for different periods of pregnancy, because there can be wide variations in the values among various laboratories. A recent trend is to express the AFP level as multiples of medians for that period of pregnancy. This makes interlaboratory comparisons easier. AFP levels could be elevated for other reasons such as twin pregnancy, placental hemorrhage, etc. If the AFP levels are abnormally elevated, the trend needs to be ascertained by repeating the test after 1 or 2 weeks. The result also needs to be correlated with a detailed ultrasonography targeting fetal organogenesis. The management protocol that is followed in the IREP ${ }^{[63]}$ is given in Figure 2.

Of late, ultrasonography that can detect several fetal malformations has become an integral part of antenatal check. Early detection of malformations such as spina bifida and meningomyelocele require careful ultrasonography by experienced persons. Amniocentesis and cord blood analysis may have to be resorted to in selected cases where fetal karyotyping also may be required.

\section{Counseling the Family when an Abnormality is Detected}

It is very important to offer counseling to the patient and the family prior to and after undergoing screening procedures. The family would require delicate and detailed counseling if a serious malformation had been detected. The sensitivity and specificity of the findings are also required to be explained to the family. Care should be taken to explain in simple terms

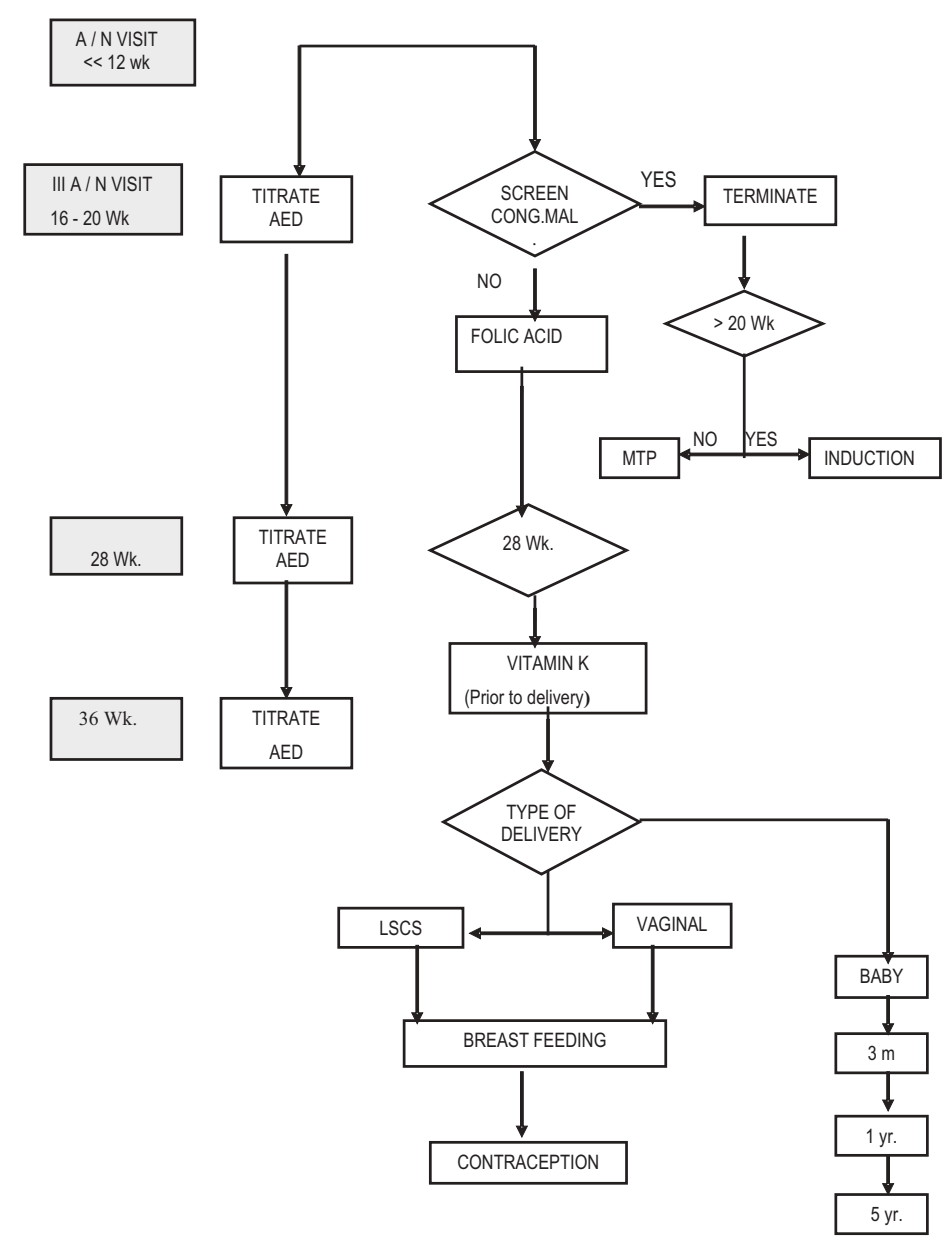

Figure 2: Algorithm (according to the Indian Registry of Epilepsy and Pregnancy) for following up pregnancy in women with epilepsy 
the type of malformation that is identified and its possible impact on the fetal survival and quality of life. The various options available to the family, such as termination of pregnancy, continuation of pregnancy, and the scope of fetal surgery can be explained to the couple.

AEDs that induce hepatic C450 enzyme system appear to be associated with vitamin $\mathrm{K}$ deficiency in the newborn. Their use can result in hemorrhagic disease of the newborn, leading to intraparanchymal and intracerebral hemorrhage. Such babies may show elevated levels of protein induced by vitamin $\mathrm{K}$ absence (PIVKA). Administration of vitamin $\mathrm{K}_{1}$ to the mother can help prevent hemorrhagic disease of the newborn. ${ }^{[55]}$ It is generally recommended that pregnant WWE on enzyme-inducing AEDs should be prescribed vitamin $\mathrm{K}_{1}$ (10 mg/day) during the last month of pregnancy. These neonates should receive the customary dose of injection vitamin $\mathrm{K}_{\mathrm{l}} \mathrm{mg}$ on day 1. The obstetrician should plan the type of delivery based on the obstetrical indications. Nearly one-third of our patients required caesarian section.

\section{Postpartum Management}

The AEDs used in the third trimester should not be continued in the first three months postpartum without any alterations in the dosages. Some patients would experience exacerbation of seizures during this period, which was attributable to sleep deprivation and physical exhaustion. It is helpful to arrange with the family members to share some aspects of caring for the newborn to avoid undue physical and emotional stress.

\section{Breast feeding}

Most of the AEDs tend to cross in to the breast milk in inverse relation to their protein binding (Table 6). Newer AEDs tend to pass in to breast milk in greater concentration than older drugs. ${ }^{[56,57]}$ The benefits of breast-feeding probably far outweigh the potential risk to the infant. Nevertheless, infants need to be carefully monitored for any untoward effects attributable to AED exposure through breast milk. Monitoring of infant serum drug concentrations is advisable but not mandatory. ${ }^{[58]}$ The general recommendation is to continue breastfeeding, but the feeds may be given before the woman takes her AED doses. Spacing and contraception

\section{Table 6: Antiepileptic drugs in breast milk as a proportion of blood levels}

\begin{tabular}{lc}
\hline Antiepileptic drug & Proportion appearing in breast milk (\%) \\
\hline VPA & $<10$ \\
Phenytoin & 20 \\
CBZ & 40 \\
Phenobarbitone & 50 \\
Primidone & 80 \\
LTG $^{[45]}$ & 61 \\
TPM $^{[1]}$ & 86 \\
Levetiracetam $^{[2]}$ & \\
Oxcarbazepine $^{[2]}$ & 80 \\
Zonisamide $^{[3]}$ & $41-57$ \\
\hline
\end{tabular}

The family needs to be counseled about the need for proper spacing of childbirth from the interest of the mother and baby. Oral contraceptives, especially low estrogen preparations and progesterone implants, may have reduced efficacy when used along with enzyme-inducing AEDs (PHT, CBZ, OXB, and PB). TPM may reduce the ethinyl estradiol level by a different mechanism. In presence of such AEDs, it may be necessary to use oral pills with more than $50 \mu \mathrm{g}$ of estrogen. Non-enzymeinducing AEDs such as VPA, LTG, and GBT may not interfere with oral contraceptive pills. Medroxyprogesterone depot injections taken once in 3 months or intrauterine devices can be used as alternate methods of contraception.

\section{Conclusion}

WWE have several special problems related with pregnancy, which need careful attention from the attending neurologists and obstetricians. It is comforting to know that majority of WWE can have safe pregnancy and childbirth. Fetal malformations attributable to exposure to AEDs occur in a small proportion of instances only and appropriate preconception management can probably reduce this risk.

\section{References}

1 Sridharan R, Murthy BN. Prevalence and pattern of epilepsy in India. Epilepsia 1999;40:631-6

2 World Population Prospects: The 2004 Revision and World Urbanization Prospects: The 2003 Revision, http://esa.un.org/unpp, accessed on 27 September 2005; 4:30:25 AM.

3 Thomas SV, Deetha TD, Kurup JR, Reghunath B, Radhakrishnan K, Sarma PS. Pregnancy among women with epilepsy. Ann Indian Acad Neurology $1999 ; 2: 123-8$

4 Grudzinska B, Kazibutowska Z, Mierzwa E, Pierzchala K, Rosciszewska D, Zawisza L. Fertility in the population of women with epilepsy. Neurol Neurochir Pol 1979;13:497-502

5 Krauss GL, Brandt J, Campbell M, Plate C, Summerfield M. Antiepileptic medication and oral contraceptive interactions: a national survey of neurologists and obstetricians. Neurology 1996:46:1534-9.

6 Russell AJ, Macpherson H, Cairnie V, Brodie MJ. The care of pregnant women with epilepsy: a survey of obstetricians in Scotland. Seizure 1996;5:271-7. Herzog AG. Reproductive endocrine considerations and hormonal therapy for women with epilepsy. Epilepsia 1991:32:S27-33.

8 Reghunath B. Neuroendocrine aspects of epilepsy and pregnancy in Sanjeev V. Thomas (ed) Proceedings of Workshop on fertility and pregnancy among women with epilepsy. Kerala Registry of Epilepsy and pregnancy, Trivandrum. 1998:7-11.

9 Marcus EM, Watson CW, Goldman PL. Effects of steroids on cerebral electrical activity. Epileptogenic effects of conjugated estrogens and related compounds in the cat and rabbit. Arch Neurol 1966;15:521-32.

10 Nicoletti F, Speciale C, Sortino MA, Summa G, Caruso G, Patti F, et al. Comparative effects of estradiol benzoate, the antiestrogen clomiphene citrate and the progestin medroxyprogesterone acetate on kainic acid-induced seizures in male and female rats. Epilepsia 1985:26:252-7.

11 Logothetis J, Harner R, Morrell F, Torres F. The role of estrogens in catamenial exacerbation of epilepsy. Neurology (Minneap) 1958;9:352-60.

12 Backstrom T, Zetterlund B, Blom S, Romano M. Effects of intravenous progesterone infusions on the epileptic discharge frequency in women with partial epilepsy. Acta Neurol Scand 1984;69:240-8.

13 Commission on classification and terminology of the International League against epilepsy1989 Proposal for revised classification of epilepsies and epileptic sydromes. Epilepsia 1989:30:389-99.

14 Knight AH, Rhind EG. Epilepsy and pregnancy: a study of 153 pregnancies in 59 patients. Epilepsia 1975;16:99-110.

15 Thomas SV, Devi CC, Radhakrishnan K, Joshua CS. Seizure pattern during pregnancy and puerperium among women with epilepsy. Epilepsia 2000;41:198-9.

16 Morrell MJ, Montouris GD. Reproductive disturbances in patients with epilepsy Cleve Clin J Med 2004;71:S19-24.

17 Artama M, Isojarvi JI, Raitanen J, Auvinen A. Birth rate among patients with epilepsy: a nationwide population-based cohort study in Finland. Am J Epidemiol 2004;159:1057-63.

18 Cramer JA, Jones EE. Reproductive function in epilepsy. Epilepsia 1991:32:S19-26. 
19 Polson DW. Polycystic ovary syndrome and epilepsy-a gynaecological perspective. Seizure 2003:12:397-402.

20 Rotterdam ESHRE/ASRM-Sponsored PCOS Consensus Workshop Group. Revised 2003 consensus on diagnostic criteria and long-term health risksrelated to polycystic ovary syndrome. Fertil Steril 2004:81:19-25.

21 Meo R, Bilo L. Polycystic ovary syndrome and epilepsy: a review of the evidence. Drugs 2003;63:1185-227.

22 Isojarvi JI, Rattya J, Myllyla VV, Knip M, Koivunen R, Pakarinen AJ, et al. Valproate, lamotrigine, and insulin-mediated risks in women with epilepsy. Ann Neurol 1998;43:446-51.

23 Bauer J, Isojarvi JI, Herzog AG, Reuber M, Polson D, Tauboll E, et al. Reproductive dysfunction in women with epilepsy: recommendations for evaluation and management. J Neurol Neurosurg Psychiatr 2002;73:121-5.

24 Sindhu K, Thomas SV, Ajaykumar B, Sylaja PN, Sulekhadevi PB, Jacob S. Complications of pregnancy and delivery in women with epilepsy. Epilepsia 2005;46:84.

25 Speidel BD, Meadow SR. Maternal epilepsy and abnormalities of the fetus and newborn. Lancet 1972;2:839-43.

26 Anderman E, Dansky L, Kinch RA. Complications of pregnancy, labor and delivery in epileptic women. In: Janz, D, Dam M, Richens A, Bossi L, Helge H, Schmidt D. (editors) in Epilepsy, pregnancy and child. Raven Press: New York; 1982. p. 61-74.

27 Richmond JR, Krishnamoorthy P, Andermann E, Benjamin A. Epilepsy and pregnancy: an obstetric perspective. Am J Obstet Gynecol 2004;190:3719.

28 Olafsson E, Hallgrimsson JT, Hauser WA, Ludvigsson P, Gudmundsson G. Pregnancies of women with epilepsy: a population-based study in Iceland. Epilepsia 1998;39:887-92.

29 Hiilesmaa VK. Pregnancy and birth in women with epilepsy. Neurol 1992;42:811.

30 Teramo K, Hiilesmaa V, Bardy A, Saarikoski S. Fetal heart rate during a maternal grand mal epileptic seizure. J Perinat Med 1979;7:3-6.

31 Diaz Romero RM, Garza MS, Molina DG. Facial anthorpometric measurements in offsprings of epileptic mothers. Epilepsia 1999;40:194.

32 Janz D, Fuchs U. Are anti epileptic drugs harmful during pregnancy? Dtsch Med Wschr 1964:89:241-8.

33 Meadow SR. Anticonvulsant drugs and congenital abnormalities. Lancet 1968;2:1296.

34 Janz D. On Major Malformations and Minor Anomalies in the offspring of parents with epilepsy: Review of the literature. In: Epilepsy, Pregnancy, and the Child. D. Janz, M. Dam, A. Richens et al (editors). Raven Press: New York; 1982. p. 211-22.

35 Samren EB, Van Duijn CM, Koch S, Hiilesmaa VK, Klepel H, Bardy AH, et al. Maternal use of antiepileptic drugs and the risk of major congenital malformations: A joint european prospective study of human teratogenesis associated with maternal epilepsy. Epilepsia 1997;38:981-90.

36 Wide K, Winbladh B, Kallen B. Major malformations in infants exposed to antiepileptic drugs in utero, with emphasis on carbamazepine and valproic acid: a nation-wide, population-based register study. Acta Paediatr 2004;93:174-6.

37 Holmes LB, Wyszynski DF, Lieberman E. The AED (antiepileptic drug) pregnancy registry: a 6-year experience. Arch Neurol 2004;61:673-8.

38 Wyszynski DF, Nambisan M, Surve T, Alsdorf RM, Smith CR, Holmes LB. Antiepileptic Drug Pregnancy Registry. Increased rate of major malformations in offspring exposed to valproate during pregnancy. Neurology 2005:64:961-5

39 Meischenguiser R, D'Giano $\mathrm{CH}$, Ferraro SM. Oxcarbazepine in pregnancy: clinical experience in Argentina. Epilepsy Behav 2004;5:163-7.
40 Montouris G. Safety of the newer antiepileptic drug oxcarbazepine during pregnancy. Curr Med Res Opin 2005;21:693-701.

41 Cunnington M, Tennis P. International Lamotrigine Pregnancy registry Scientific Advisory Committee. Lamotrigine and the risk of malformations in preg nancy. Neurol 2005:64:955-60.

42 Nicolson A, Appleton RE, Chadwick DW, Smith DF. The relationship between treatment with valproate, lamotrigine and topiramate and the prognosis if the idiopathic generalized epilepsies. JNNP 2004;75:75-9.

43 de Haan GJ, Edelbroek P Segers J, Engelsman M Lindhout D, DevileNotschaele $\mathrm{M}$, et al. Gestation-induced changes in lamotrigine pharmacokinetics: a monotherapy study. Neurology 2004;63:571-3.

44 Liporace J, Kao A, D'Abreu A. Concerns regarding lamotrigine and breastfeeding. Epilepsy Behav 2004;5:102-5.

45 Ohman I, Vitols S, Tomson T. Lamotrigine in pregnancy: pharmacokinetics during delivery, in the neonate, and during lactation. Epilepsia 2000;41:70913.

46 Sabers A, Dam M, Rogvi-Hansen B, Boas J, Sidenius P, Laue Friis M, et al. Epilepsy and pregnancy: lamotrigine as main drug used. Acta Neurol Scand 2004; 109:9-13

47 Morrell MJ. Guidelines for the care of women with epilepsy. Neurology 1998;51:S21-7.

48 Craid J, Russell A, Morrison P, Robertson I, Parson L, Morrow J. The antiepileptic drugs in pregnancy a registry in the UK to determine their safety. Epilepsia 1999;40:196.

49 Tomson T, Perucca E, Battino D. Navigating toward Fetal and Maternal Health: The Challenge of Treating Epilepsy in Pregnancy. Epilepsia 2004;45:1171-5.

50 Ohman I, Vitols S, Luef G, Soderfeldt B, Tomson T. Topiramate kinetics during delivery, lactation, and in the neonate: preliminary observations. Epilepsia 2002;43:1157-60

51 Briggs DE, French JA. Levetiracetam safety profiles and tolerability in epilepsy patients. Expert Opin Drug Saf 2004;3:415-24.

52 Long L. Levetiracetam monotherapy during pregnancy: a case series. Epilepsy Behav 2003;4:447-8.

53 Vinten J, Adab N, Kini U, Gorry J, Gregg J, Baker GA. Neuropsychological effects of exposure to anti convulstant medication in utero. Neuro 2005:64:949-54.

54 Thomas SV, Indrani L, Devi GC, Jacob S, Beegum J, Jacob PP, et al. Pregnancy in women with epilepsy: preliminary results of Kerala registry of epilepsy and pregnancy. Neurol India 2001;49:60-6.

55 Cornelissen $M$, Steegers-Theunissen $R$, Kollee L, Eskes T, Motohara K Monnens LL. Supplementation of vitamin $K$ in pregnant women receiving anticonvulsant therapy prevents neonatal vitamin $\mathrm{K}$ deficiency. Am J Obstet Gynecol 1993;168:884-8.

56 Pennell PB. Antiepileptic drug pharmacokinetics during pregnancy and lactation. Neurology 2003;61:S35-42.

57 Ohman I, Vitols S, Luef G, Soderfeldt B, Tomson T. Topiramate kinetics during delivery, lactation, and in the neonate: preliminary observations Epilepsia 2002:43:1157-60.

58 Bar-Oz B, Nulman I, Koren G, Ito S. Anticonvulsants and breast feeding: a critical review. Paediatr Drugs 2000;2:113-26.

59 Ohman I, Vitols S, Luef G, Soderfeldt B, Tomson T. Topiramate kinetics during delivery, lactation, and in the neonate: preliminary observations. Epilepsia 2002; 43:1157-60.

60 Bulau P, Paar WD, von Unruh GE. Pharmacokinetics of oxcarbazepine and 10-hydroxy-carbazepine in the newborn child of an oxcarbazepine-treated mother. Eur J Clin Pharmacol 1988;34:311-3.

61 Kawada K, Itoh S, Kusaka T, Isobe K, Ishii M. Pharmacokinetics of zonisamide in perinatal period. Brain Dev 2002;24:95-7. 